\title{
A LITERATURA FEMININA NO BRASIL CONTEMPORÂNEO
}

\author{
Nelly Novaes Coelho
}

RESUMO: Reflexūes acerca da força inventiva e tas peculiarichıles formais e/ou lemáticas cha criaçẫo literíria, produzich pela mulher brasileira, Jesde os anos 60/70 até o momento (1989); e analisada em relaçĩo à crise súcio-cultural ainla em curso em nosso século.

Entre as conclusúes provisórias a que se puxle chegar, pela análise dh produçâo de vinte escriloras (selecionadas em funģio nĩo só do valor intrínseco de suas obras, mas também como representalivas ths vårias tendências da fiç̧io contemporânen), registramus: a consciência de que à linguagem puética ou ficcional compete dar realidade definitiva às novas vivências; a presençn de problemáticas espećficas tu "cterno feminino" em transformação; a inexistência de uma sinlaxe linguística especificamente "feminina" ( uma obra não depende do sexo do autor ou autora,, mas cho talento de cada um; e finalinente a importância basilar que essa literalura nđłyuire mara um possível conhecimento ou conscientizaçẫo das transformaçöes estruturais que atingem hoje a Suciedace e a Cultura herchdas.

Entre os fenômenos mais significativos desle último quarto de século, no âmbilo da Literalura e da Crílica, está sem dúvida a crescente importância que vem assumindo três áreas de criação literíria que, tradicionalmente, cram ignoradas ou minimizadas pela cultura oficial. Referimo-nos à literalura escrila pela mulher; à literatura destinada às crianças ou jovens e à literatura "negra".

Eslá claro que, muito mais do que simples moda, esse Iriplo interesse arraiga em um fenômeno cultural muilo amplo: a inegável emergência do "diferenle": o espaço conquistado pelas vozes "divergentes" no seio da Sociedade e a descoberta da alteridade ou do Outro (via de regra oprimido, pelo tradicionalismo instituído) que impedia (ou impede?) ao Eu sua verdadeira auto-descoberta.

Já não há dúvida de quee, na base das mudanças que dia-a-dia alleram o mundo herdado do passado, está a gradaliva e crescente mudança dos conceitos que definiam, nos planos social, cconômico e político, as figuras da Mulher, da Criança e das chamadas "raças inferiores" (as que, escravizadas pelo branco, ajudaram a consırução desıa nossa esplêndida civilização-do-progresso, agora em fase de troca-de-pele.) 
Nessa ordem de idéias, insere-se o chamado boom da Lileralura Inlantil a partir de meados dos anos 70; bem como a tímida produção literária ou crílica da "negritude" (e lambém a redescoberta da nossa "mitologia indigena"). que se lem manifestado, entre nós. E, principalmente, se compreende a lorça com que a Literalura Feminina se vem impondo à Crílica, como um lenómeno especial a exigir a alenção; mesmo a despeito das muitas vozes (inclusive de muitas escritoras...) que vêem nessa distinçã̃o (feminino versus masculino) mais uma discriminação.

A nosso ver, muito longe de consistir "discriminação" ou de se identifïar com un novo preconceito (a pretensa substituiçĩo do Machismo pelo Feminismo), a preocupação especial que, nestes últimos anos, a Lileratura Feminina vem desperlando nos leitores e nos estudiosos, se liga ao bato de que a melamorloseem-marcha no mundo de hoje lem, na mulher, a sua pedra-de-toque.

Já se sabe à saciedade que, entre as grandes revoluçócs inovacloras a que nosso século vem assistindo, a que arraiga na translormação do mundo feminino é dass mais decisivas, pois atinge as basses do Sistema de relaçóes vigentes no mundo civilizado que herdamos.

Note-se, ainda, que a alenção que a produção literária das mulheres vem exigindo da Crítica, como fenômeno especílico que é, cm meio à produção literária geral, não se identifca com uma intençióo judicalliva. Não se trala de saber se a literatura "feminina" é melhor ou pior do que a "masculina". Obviamente já nào lêm mais sentido as discussões que se centravam na questão do "valor" maior ou menor de um ou oulra; pois já ć ponto pácílico o falo de que valor litcrírio não lem sexo. Tanto há os grandes escritores ou escritoras, como os meramente bons, mediocres ou péssimos... O confronto entre ambas as produçōes levam facilmenle à conclusão de que homens e mulheres se igualam em forçă ou energia criativa (descle que kenham idênticas oportunidades de desenvolvimento cultural). e que a maior ou menor "espessura" literária de cada obra depende exclusivamente da maior ou menor "qualiclade" do espírito que a produz, seja de homens ou de mulheres.

Nesse sentido, a Crítica atraída pela produção literária da mulher tem-se preocupado basicamente em descobrir o que é, essa literalura; como se constrói c por que trilla determinados caminhos (lemáticos, estruturais, estilílicos, idcológicos, etc.) Ou, pelo menos, lem sido esse o "horizonte de expeclativa" que permanece em nosso espírito quando, diante de eada livro ou nova autora, entregamo-nos à leitura è à análise, tentando chegar ao alćm-lexto ou ao subtexto, onde estaria oculto o essencial.

Para nós, a ponte para esse "diálogo com a esfinge" (que é cacla obra literária autêntica) esłá nas relaçōes eslabelecidas entre a obra c o momento histórico-cullural em crise, que a gerou. Em maior ou menor grau, a Crítica literária attual empenha-se em deteclar as relaçōes entre a obra c a almosfera cultural em que cla "respira". E, a partir dessas relaçōes, caracterizar a linguagem criada, a vibração de sua matéria poćlica c os inúmeros aspectos que fazem dela umá obra literária autêntica e "contemporâneal". 
Talvez não seja exagero alïrmar (só o tempo o dirai...) (juc, altualmente, a produçāo litcrária das mulheres ć muito mais expressiva do que a dos homens, em se Iralando de testemenho ou reflexo da crise civilizacional ainda em processo. Crise yue abala muito mais fundo os valores ou padróes do comporlamento "lieminino", do que átinge os padrócs "masculinos". Daí, por exemplo, a "busca da identidacle", - uma das lorças motrizes da literatura altaal, seja mais exasperada na criação lilerária das mulheres, do que na dos homens.

Nosso percurso, meste breve ensaio sobre a lilcralura leminina no Brasil, procurará estabelecer os nexos entre crise e criaģöo literíria, como aberlura de caminhos à comprecensão de suas peculiaridades. Comecemos pelo mais geral e abrangente.

\section{A CRISEE DA MULIIER NO SÉCULO XX}

Analisando a crise da mulher em nosso século, o lilósolo Julian Marías chama a alceção para o falo de que a palaura "crise" lem a mesma raiz que "crítica" e que o signilicado predominanle de "crise" é desorienlação, não de um indivíduo ou grupo, mas de una colctividade, - o que dá o carailer histórico que lodas as crises apresentam. Nessa ordem de idéias, a "crise". que vem sendo viviela pela mulher cm nosso século, se idenlilica com uma crise histórica, gerada pela desorienlação de homens e mulheres diante de uma avalanche de inlerrogações, postass pelos novos lempos, sem que se enconlrem resposlas seguras e indisculíveis para cadla uma delas. Diz Julian Marías:

"No século XX, a mulher se pergunla por si mesma. Dir-se-á: não o läazia anles? A mulher nĩo se pergunlava por si mesma? Não no mesmo grau, com as mesmas frequência e inlensidade. Carda mulher (como calda homem) se pergunta por si mesma. A vida humana consiste em calla um pergunlar-se por si mesmo e ir dando um significado ao nome próprio yue cáda um de nós possui: isso é nossa biogralia. Mas normalmente, as mulheres pergunlavam calu amo por si mesma; pois em outras épocas daval-se por suposto o quie á mulher; as mulheres acreditavam saber 0 que era ser mulher (ou o que devia ser) ./.../ inclusive o que cra mulher exemplar, pareceu óbvio na maioria dass épocas ./... Alualmenle não o é. Ao lado da pergunta que cada mulher laz. a respeilo de si mesma, singularmenle, há uma questão prévia: Que quer dizer "ser muller"? Que signilicado lem? Agora, precisamente agora, nesla época em que vivemos. Mass esta yuestão nĩo é exclusiva dela, porque o homem está referide ì mulher, nisso consiste ser homem, do mesmo modo que ser mulher consiste em estar referida ao varão. A crise em que a mulher se encontra quanto à sua própria condição envolve imediatlamente o homem".

Temos aí o problema colocado com clareza. Na verdale, em todas as ćpocass, $\mathrm{c}$ das mais variadas maneiras, 0 munelo feminino loi apoio e espaço concreli- 
zador das idéias, crenças, conquistas ou inovaçōes do mundo masculino... Assim, nada mais natural que agora também esleja sendo o cspaço por excelência onde o "novo" se eslá forjando, em meio a desencontros, perplexidades, acertos c desacerlos. Com a diferença de que, agora, um dos elementos-chave da mudança-cmprocesso é o próprio mundo feminino, é a própria condição-de-mulher que lenla se redescobrir e se reequacionar em sintonia com as novas forças imperantes. Como diz, Marina Colasanti:

"... somos mulantes, mulheres em transição. Como nós, não houve outras antes. $E$ as que vierem depois serāo diferentes. Tivemos a coragem de começar um processo de mudança. E porque ainda está em curso, eslamos tendo que ter a coragem de pagar por cle. /.../Saímos de um estado que embora insatisfatório, cmbora esmagador, estava estruturado sobre certezas. Isso foi onlem. Alé então ninguém duvidava do seu papel. Nem homens, nem muilo menos mulheres./.../Mas essa cerleza nós a quebramos para poder sair do cercado".

Só alravés dessa perspectiva, a de um mundo em mulação acelerada de suas anligas bases, é que se pode compreender melhor as transformações que se vêm processando no voz feminina que, nestes últimos cinqüenta anos e cada vez com mais força e essencialidade, se vem fazendo ouvir na Lileralura Brasileira.

Há uma voz especificamente "feninina"?

Uma das perguntas mais frequenles que se colocam hoje nas discussões sobre a Literatura Feminina, diz respeito à especificidade da voz que ali fala. Haveria um discurso essencialmente "feminino"? Existiria uma linguggem ferminina na Arle? Evidentemente, não são pergunlas ociosas ou graluilas e têm sua razão de ser, uma vez que em passado recente acredilava-se em diferenças de ordem biológica que determinariam a criação artística do homcm c da mulher: o primeiro, sendo alivo, forle e dinâmico seria dono de uma arle idêntica à sua nalureza viril; enquanto a segunda, sendo sensível, frágil, psicologicamente sulil, afetiva, ingênua, elc. criaria uma arte também delicada e frágil...(como vemos, já nessa diferenciação esłá palente a presença do modelo-de-comporlamento que se considerava ideal para a mulher...)

Hoje, as diferenciações continuam a ser pesquisadas, principalmente via psicanálise junguiana, que aponta para um simbólico masculino, - amimus, e para um simbólico feminino, - anima. Entretanto, as análises têm provado que nem sempre lais simbolismos correspondem ao sexo correlativo... O que nos leva a concluir que a diferenciação entre a criação literária masculina e feminina nāo pode ser decidida exclusivamente no âmbito do biológico.

Há ainda as pesquisas ao nível do discurso. que apontam como caracleríslicas "femininas" na literatura contemporânea: a palavra fragmentada; a tendência 
a impregnar a palavra escrila com elementos da oralidade; a insistência no próprio emissor (o discurso voltado para o sujcito que fala); a projeção da linguagem no nível simbólico; a tendência a explicar o universo em lugar de interpretá-lo; a predileçño pelo "delalhe", como ocorre com o relato popular; clc. (Cr. artigo de Marla Traba)

Como é fácil perceber, lais diferenciações estilísticas ou esıruturais são comuns à linguagem moderna, desde seus primeiros "inventores". Resullam da crise cultural que o nosso século vem vivendo c, $\mathrm{cm}$ absolulo, seriam caraclerísticas de uma maneira de dizer ou de um discurso literário feminino. Adolado por homens ou mulheres, o estilo contemporâneo, não eslabelece nenhuma diferenciação plausível entre a escrita do homem e a da mulher.

Não haveria então nenhuma literatura feminina? A literatura scria uma criação transcendental, que se concretizaria em plano acima das contingências exislenciais de classe, raça, sexo, elc,? Evidentemente que não. Ninguém duvida que a Litcratura ou a Arle em geral, nada mais são do que formas especiais de relaçōes que se estabelecem entre os homens e suns circunstîncias de vida, como dizia Orlega y Gasset. Ou melhor, a nalureza da Arte depende do que acontece no conlexto histórico, econômico, social, de classe ou de dominação, em que está "siluado" o artista ou o escritor.

Nesse senlido, não é possível pensarmos a criação arlística ou literária, em sua verdade maior, sem pensarmos na Cultura em que ela está imersa. É através dessa perspectiva que, sem dúvida, podemos falar em uma literatura feminina e uma literatura masculina... pois as coordenadas do Sistema Social/Cultural ainda vigente estabelecem fundas diferenças entre o ser homem e o ser mulher. Dessa diferença deriva, evidentemente, certas peculiaridades que podem ser delectadas na criação lilerária de um e de outro.

A grande mudança, que o nosso século trouxe para a vida da mulher, foi evidentemente fator determinante para o surgimento c expansão de uma literatura feminina que, em qualidade, está no mesmo nível da produzida pelos homens.

\section{A "NOVA" MULIIER}

Dentre os fatores mais importantes que aluam na "geslação" dessa "noval" mulher (cuja presença na Sociedade se faz cada dia mais forle), destacamos o amadurecimento crescente de sua consciência crílica. Consciência yue a força a se posicionar, não só em relaçĩo à falência do modelo-de-comporlamento feminino, herdado da Sociedade Tradicional (a Sociedade cristã/burguesa/liberal paIriarcal/capitalista que vem sendo questionada e abalada em seus alicerees desde o início do século), como lambém quanto à interdependência existente ou imposiçōes do contexto sócio-cultural em que essa criação surge.

Desse amadurecimento crítico resulta, ba lileratura, a presença cada vez mais nítida de uma nova consciência feminina que tende, cada vez com mais for- 
ça e lucidez, a romper os limiles de seu próprio "cu" (Iradicionalmente vollado para si mesmo, em uma vivência quase aulofágicai), para mergulhár na esfera do "outro", - a do ser humano parlicipe desic mundo cm crise. Daí que o eu-quefala, na literatura feminina mais recente, se revele cada vez mais claramente como "nós". Em suma, nesıes últimos anos, os problemas limiladamente "femininos" lêm-se alargado no sentido de se revelarem ilimilamente "humanos".

De uma literatura lírica/sentimental (gerada pela conlemplação emoliva), cujo referencial de valores se paulava pelos padröes que a sociedade cristã/paIriarcal defendia como únicos e absolutos (castidade, submissão à auloridade do homem, discriçāo, ingenuidade, paciência, eılc.) a mulher chegou a uma lileralura Épica/exislencial (gerada pela ação élica/passional), que expressa claramenle o rompinkento da polaridade maniqueista, inerente à imagem-padrão da mulher, anjo/demônio, esposa/corlesã, "ânfora do prazer"/"porla do inferno", elc. Em lugar de optar por um desses comportamentos antagônicos, a "nova" muller assume ambos e revela a ambiguidade inerenle ao ser humano.

Isso significa que, da submissño ao "modelo", ela passa gradalivamente à sua transgressio e nos anos mais recenles à busca de uma nova imagem que the permita auto-identificar-se novamente com segurança. Na área da poesia ou da ficção, vem sendo esse o caminho seguido. Caminho que explica lambém a exâcerbação do Erotismo, como marea inequívoca de nossos lempos. De um bloqueio absolulo ao sexo, passa-se à liberaçâo lambém alssoluta. Entretanto, algo eslá mudando: o Amor está sendo redescoberio, em novas dimensões...

\section{A POESIA}

No ambito da Poesia, as vozes femininas que (lal com as dos homens) se fazem ouvir a partir dus anos 60 , embora apresentanclo as mais variadés tenclências de estilo, processos ou temas, apresentam um traço comum que as aproxima ce identifica como participantes de uma mesma forģa criadora: a consciência experimentalista, no sentido do reajıstammento da lingıngem às solicilações dos novos tempos c 0 impulso dinâmico de integração do ser humano e da poesia no processo histórico cm desenvolvimento. Isto é, uma nova confiança na condição humana, devido à sua possível Iranscendência alravés da Arle e do Espírito. Ou ainda, una nova inlerrogaçióo do ser-poela. $O$ amor desaparece como lema ou passa para segundo plano. Em primciro, aparece predominantemente o tempo e suas mutaçōes.

E o caso de vozes como as de HILDA HILST (Odes Fragmentirias-61; Trajetória do Ser - 66 c Exercicios para ımma idéin-67); RENATA PALLOTTINI (Lirro de Sinnetos-61; A Faca e a Pedra-65; Os Arcos da memóriu-71); NEIDE ARCHANJO (Primeiros Ofícios da Memórin-64; O Pocta ltinerame-68; Poesia na Praça-70..) YEDA SCHMALTZ (Caminhos de mim-64. Tempo de Semear69..) EUNICE ARRUDA (É Tempo de Noite-60; O C.Irio Batido-6.3; As Coisas Efêmeras-64...); IDA LAURA (Poema Cíclico-62; Antecipação-6S; Nova ldade- 
COLLIIO, Nelly Novaes. A liternlum feminina no Brasil conlemporâneo. Lingua e

Liternturn, v. 16, n. 19, p. 91-101, 1991.

69); LAIS CORREIA DE ARAUJO (Cantochio-65): FULVIA DE CARVALHO LOPES (De Amor e Morte-63, Poliedro-66, Satumo Satu'no-69, O Ser Impossirel-70..); YONE GIANETTI (A fala e a Forma-63, Rosa Dialética-75); IVETE TAUNUS (Canto de Amor e Morte para um Rei-63); LÚCIA RIBEIRO DA SILVA (Jogo Fixo-66, Estar para Ser-73); LUPE COTRIM GARAUDE (Entre a Flor e o Tempo-61, Câmticos da Terra-63, O Pocta e o Mundo-63, Poemas no OItro-69...); ILKA BRUNILDE LAURITO (Janelu de Apartamento-68); STELLA LEONARDOS (Rumanceiro de Esticio-62, Tempos Alados-64, Geolirica-66, Camtabile-67, Rapsúdia-68, Camtares na Amtemmina-70...); STELLA CARR (Três Viagens no men Rosto-65, Matéria de Abismo-65, Caderno de Capazul69..) CORA CORALINA (Pocmas dos Becos de Goińs-65); NÚBIA MARQUES (Um Ponto e duas Divergentes-59, Dimensóes Póéticas-61, Balatus do Imitil Silêncio-64); MARIA JOSÉ GIGLIO (Liz no longe-60, Poemas no Amndo-62, 0 Labirinto-64).

Em lodas cssas vozes poćticas estão presenles não só a consciência da tarefa criadora que cabe ao ser-pocta, neste mundo-em-caos, como a sondagem da palarra poética Iransformada ela mesma em poema.

E no decorrer dos anos 70/80, que se aprofunda a consciência crítica da mulher $\mathrm{cm}$ relação a si mesma e a larefa que lhe caberia desempenhar não só no âmbito da criaçño literária, mas também no da socicdade cm-mudança. Dá-se uma espécic de explosão da fala feminina, é como se nāo houvesse nenhum limite, nenhuma fronleira a ser respeilada. En busca de uma nova idenlidade, é como se as mulheres tivessem a audícia de não quererem mais se sujeilar à antiga imagem e por não conseguirem encontrar a nova, assumem a mesmo lempo uma paradoxal mulliplicidade de identidade conflituantes... Dilduem-se as fronteiras entre poesia e ficção. Ou melhor, a lieção, uma vez perdicla a lógica ordenadora das coisas c scres, vê-se obrigata a trabalhar com a intuição c, tentar organizar, cm discurso, a fragmenlação do mundo que the cabe expressar. Daí que poctas passem lambém a escrever fiç̧̃̃o. Como é o caso de: HILDA HILST(Ficção: Fhuxofloema-70, Qadós-73, Fiçōes-77, Tu nöo te movés de ti-80, A Obscena Senhora D-882, Com os meus olhos de cão-86 c Poesia : Da Morte, Odes Mínimas80, Cantares de Pedra e Predileçño-83...); HELOISA MARANHÃO (Poesin Castelo Interior e Moradas-74/78; Fiç̧̃o: Lucrécin-79, Florinda-82, Dona Leonor Teles-85 e Rainha de Nararra-86); ADÉLIA PRADO (Pocsia: Bagagem-76, O Cornção Disparalo-78, Terra de Samta ('ruz-78 e O Pelicano-87); Fiç̧ão: Solte os Cachorros-79 e Cacos para um ritral-80); YÊDA SCHMALTZ (Pocsia: Secreta árin-73, O Peixenmuta-75, A Alquimia dos Nós-79, Miserere-80, Anima men-84 e Baco e Anas brasilèras-85, Ficção: Atalanta-87). Todas clàs, escritoras da mais alla lempertura criadora, cujas obras resullam "exemplares" como expressão do lèminino-em-evolução ao nível da arle-e-da-vida.

Entre as poctas de "guerra", que continuam obra já iniciada antes ou apenas se iniciam nesles 70/80, destacamos: STELLA LEONARDOS (Amanhlecência-74, Romançário-74, Romanceiro de Anita e Garibaldi-77, Cancioneiro de S. 

I.lleralura, v. 16, n. 19, p. 91-101, 1991.

Luis-81 c Mural Pernambuco-86); NEIDE ARC.IIANJO (Quirote Tango e Foxtrote-75, Escun'uçōes-80 e As Marinhuss-84);TERESA TENÓRIO (Parribola-70, O Círculo e a Pirâmide-76, Mandala-80, Noummo Selingem-81 c Pocmaceso85); MARIA DO CARMO B. C. DE MELO (Cic:lo da Solidiò)-71, Tempo Reinrentudo-72, As Circunstancias-75, Invocaçĩo de Orphè-79, Alianģa-79, c A Forģa da Paixño \& Incerteza das coisas-84); MYRIAM FRAGA (Marinhas-64, $O$ Livro dos Adynala-73, A Ilha-75, A (iddede-79, $O$ Riso no Pele-79, Magma82); LARA DE LEMOS (Para um Rei Surdo-73, Amálgama-75 c Adaga Lavraala-81); clc. Em 79, MARIA DE LOURDES HORTA publica uma antologia de poesia leminina, Palarra de mullker, que apresenta um signilicalivo panorama das diversas tendências ainda em curso.

Há ainda uma importante produção poćlica que, nos anos 70/80, reflete o período de repressão c autorilarismo em que vivemos durante o governo militar. Trata-se da "Literatura Alternativa", criada pelos poctas "marginais", isto é, aqueles que não tinham acesso aos meios tradicionais de publicação ce divulgação. Ficaram lambém conhecidos como a"geração mimeógrafo" Entre as poelas que mais se Iem distinguido nessa linha, estẫo: LEILA MICOLIS c ANA MARIA CRISTINA CÉSAR.

Nestes anos 70/80, a linguagem disciplinada e culla explode em irreverências c vulgaridades linguísticas que agridem aberlanente o sistema ou os Poderes vigentes. O palavrão, a promiscuidàde, a vulgaridade, a liberação sexual, a grosseria, a lalência da Auloridade, em lodos os níveis, sĩo assumidos como armas de combale. Em todas as áreas da criação literíria, procura-se alingir os próprios alicerces da Sociedacle lerdada. E até o momento (1989), nada resistiu incólume...

\section{A FICÇño}

É, porém, na área da Fiç̧ão (c também na do Teàtro) qué essa desagregação do tradicional e essa busca do "novo" se revelam mais contundentes ou explícitas. Mesmo por uma análise superficial da produção ficcional dos anos 70/80 pode se verificar que os principais problemas ali aluanles arraigam no questionamento do Ser e do seu Eslar-no-mundo e no experimentalismo formal ou na consciência da Palavra como agente criador do Real.

Na nova ficção feminina, o Amor (embora sempre lalenle no universo ali construído) deixa de ser 0 tema absoluto para ceder lugar às sondagens existenciais; ao ludismo da invenção literária; às fantasias intertextuais; ao questionamento político; à redescoberla do Mito ou da Histórial, - células primeiras do mundo hoje em transformação; e principalmente ao Erotisıno. Tálvez possamos dizer que esle se impóe como força primeira a dinamizar uma diversificada e significativa produção literária, empenhada visceralmente na busca de identidade em que cada escritora se entrega, sem terem conseguido, até o momento, descobrir por inleiro. Os tempos não são ainda chegados... 
Perseguindo essa multifaceladi. problemálica, surgem lendências aparenlemente bem distinlas uma da outra: o romance-monlagem, que explora os caminhos da "intertextualidade" (cf. a ficção-espetáculo de Heloísa Maranhão); a recuperação da fala arcaica (cl. Sarah Pinhciro de las Casas); a relatividade da verdade e o foco narrativo múltiplo (cf. Maria Alice Barroso em História de um Casamento); o registro labiríntico substituindo a estrulura narraliva linear (cf. Hilda Hilsı e sua ficção); a exploração dos Mitos ou da Alquimia (cf. Yêda Schmaltz), elc.,elc. (Note-se que os breves exemplos aí indicados não represenlam exclusividade, mas simples registros "modelares").

$O$ leque de problemas e tendências amplia-se cada vez mais. $O$ fragmentarismo é a pedra de loque dos diferenles estilos. Se nos anos 60 , a forma do conto é a predominante, a partir dos anos 70 , a forma do romance começa a se impor c, hoje, praticamente domina a produção de primeira linha. Sinal que já estamos nos aproximando de uma nova ordem global...pois o "romance" exige uma ordem abrangente que o conto dispensa, ou melhor, repudia... Citando algumas das escritoras c obras que têm conlribuído para e evoluçĩo da literatura deste período mais recenle, lemos:

NÉLIDA PIÑON (Guia Mapa de Gubricl Arcanjo-61; O Funductor-69; A C'asa da Paixño-72; A Força do Destino-77; A Repriblica dos Sonlwos-84...); HILDA HILST (Fhaxofloema-70; Qmás-73; Ficçöes-77; A Obscena Senlora D-82; Dona Leonor Teles-85; A Rainha de Nanarra-86...); MARIA ALICE BARROSO (Histórin de um! casamento-60; Um simples afeto recíproco-62; Nome para matu-67; Quem matou Pacífico7-69; O Globo da Morte-81; Um dia irmos rir disso utedo-84; A Saga do Caralo Inckmade-S8...); LYGIA FAGUNDES TELLES (Antes do Brile Verele-70; Seminário dos Ratos-77; As Meninas-73; Filloss Pródigos-78; A Disciplina do Amor-80; Mistério-81; Horas muras-89.); SARAH PINHEIRO DE LAS CASA (As Crespas C'muins da Primanera-79); HELENA PARENTE CUNHA (Os Provisórios-78; Corpo no Cerco-78; Maramar-80; Mullher no espello-83; Cem Mentiras de Verdade-85...) JULIETA GODOY LADEIRA (Entre Lobo e Ciño-77...); SÔNIA COUTINHO (Uma Certa Felicidade-76...); EUGÊNNIA SERENO (Um Pássaro na escuridão-66); LYA LUFT (As Parceiras-80; A Asa esquerda do Anjo-81; Reıniño da Família-82; O Qunrto Fechado-83...); ANA MARIA MARTINS (Trilogia do Emparedalo-73; Sala de Espera-78; Katmandit-83...) JUDITH GROSSMAN (O meio da pedia-70; Cantos Delituosos-85...) MÁRCIA DENSER( Tango Fantasma-70; $O$ animal dos motéis-84; Diana, a Caşadora-80); PATRÍCIA BINS (Pele Nua do Espelho-89); MYRIAM CAMPELLO (Sortilégio-81; Cerimônia da Noite-73...); BETTY MILAN (O Sexophuro-81); STELLA CARR (O Homem ck Sambaqui-75.); RACHEL JARDIM (Os Anos 40-73; Cheiros e Ruídos-75; Vazio Pleno: Relcuório do Cotidiano-76; Inventairio das C'inzas-80); MÁRC.IA KUPSTAS (C'asos de Sedirģĩo-87) elc.

Desenvolvendo-se em diferentes chaves, essa produção ficcional mais recente revela uma mulher que inlerroga e luta com a palavra no encalço de um novo conhecimento do munjo e das outros; de si mesma e do Mistério que permanece no horizonte úllimo da vida. 

L.lleraluiri, v. 16, n. 19, p. 91-101, 1991.

Como se verá pela recolla de lílulos ápui reunidos, dentre os vários caminhos escolhidos pelas escritoras, destacam-sc dois que, aparentemente antagonicos, muilas vezes se misturam. Trala-se do Erotismo e da Inejuie'tude Metafísica. Optando aberlamente pela "linguagem do corpo" e pelo "direito ao prazer do corpo" (ambos proibidos pelas normas tradicionais do viver...), a literalura crólica feminina coloca com agudez o problema da mulher de hoje, pressionada entre dois mundos: o Iradicional/opressor c o moderno/liberador. Como disse Márcia Denser em $O$ Animal dos Motéis: "As mulheres da minha geração perambulam pelo castclo $\mathrm{cm}$ ruínas do casamento. E se possuem a chave da liberdade conlerida pela pílula, nada podem fazer com cla. Deram-nos a chave, mas esqueceram de consiruir a porta".

Aí está expresso metaforicamenle o dilícil processo de liberação que vem sendo enfrentado pela mulher-sćculo XX, devido à inevilaivel inadequação enlre a "liberdade" conquistada e a estrutura tradicional ainda vigente na Sociedade. Não se pode negar que, em nosso século, o Sexo explodiu as barreitas que o mantinham na clandestinidade tradicional e se impôs como um dos mais controverlidos mitos contemporâneos. Mas a verdade é que a deslocação dos valores, que essa explosão provocou, ainda não foi resolvida. E a busca continua...

É importante notar que uma das vias escollhidas para essa busca é a do Erolismo limítrofe com a Melatísica. Um dos exemplos mais lascinantes desse "erotismo metalísico" nos é dado pelo breve-denso romance de Hilda Hilst, $A$ Obscena Senhora $D$. Rompendo os limiles impostos pelos preconceilos e pela esIreilez repetitiva de um colidiano aparentemente calmo e parado, laz-se ouvir a agônica "Senhora D": "Vi-me aláslada do centro de alguma coisa que não sei dar nome: por isso irei à sacristia, leólaga incesluosal, isso não, cu Hillé lambém chamada por Ehud, A Senhora D, cu Nadal, cu Nome de Ninguém, cu à procura da luz numa cegucira silenciosa, sessenta anos à procura do sentido das coisas".

Assim lem início a narrativa e nessa obssessiva busca, Hillé-narradora prossegue alé o final, tentando tocar o Mislćrio para lá dos limiles conhecidos, lá onde o sagrado c o profano formam uma só massa voraz e alcriadora que engole sua lucidez. A violência verbal de $A$ Obscena Senhora $D$ se identilica com a violência que devora o homem conlemporâneo, a partir do momento de conscientização, em que cle, encarando de frente o mistério de sua condição, c com lucidez, exige uma resposta racional para o caos e o calvário que parecem ser, afinal, o verdadeiro destino do Homem.

De qualquer forma, para além do poço obscuro uma indecisa luz é vislumbrada...

O espesso crolismo desse belo/terrível romance acaba por se identicar com a enorme interrogação existencial que impulsiona a busca que muilas mulheres vêm emprecendendo, na vida e na literalura, no encalço de si mesmas; do lugar que devem ocupar no mundo; e de suas possíveis relaçóes com o Mislério... 
Lileruturn, v. 16, n. 19, p. 91-101, 1991.

\section{CONCLUSÃo}

Como se poderá depreender do rápido bosejuejo de cerlas linhas da produção lilcrária feminina brasileira contemporânea, já vamos bem longe do início dessa prodıção, quando quasse a tolalidade dos escrilos se limilava àos problemas de um "cu" amoroso, frustrado pelo desamor ou mutilado pelo bloqueio do meio ambiente. Se frustraçōes c bloqueios conlinuam a haver (pois as forças opressoras continuam atuanles no mundo lodo), na literatura realizada pelas mulheres, cles surgem, agora, "lilltrados" por uma inequívoca consciência crítica, o que altera pela raiz o fenómeno vivido...

Aos nomes aqui selecionados, podcríamos acrescentar pelo menos mais umas duas dezenas de figuras alltamente aluantes na consırução da Literalura Brasileira de hoje. Conscientes do mundo aberto em que vivemos e da acelerada mulação por que cle passá, as mulheres estão se assumindo, ao lado dos homens, cono clementos participantes (vitais e decisórios e não mais, secundários ou passivos) do processo-cm-mulação.

A Poesia, a Ficção c o Teatro que clas vêm construindo, nestes úllimos anos, estāo aí para provar.

\section{BIBLIOGRAFIA}

MARIAS, Julian. A Mulher no seculo XX. SP, LiD. Convivium, 1981.

COLASAN'Il, Marina. Mullher deuqui para fréme. RJ, Nórdica, 1981.

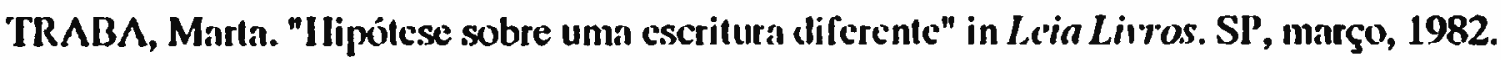

RLSUMFN: Rellexiones acerca un la fucrza inventiva y peculiaridades formales y temáticas de la creación litcraria producida por la mujer brasileńa, cescle los años 60/70, hasta el momento (1989); análisis de dicha producción ante la crisis sociocultural axin en proceso en nucstro siglo.

$\Lambda$ través del análisis de la producción de veinte escrituras (seleccionadas en función tanto del valor intríseco de sus obras quanto de su representatividad clentro de las varias tendencias de la ficción con(emporainea) llegamos a algunas conclusiones: la conscicncia de yue cabe al lenguage puético o ficcional dar realidad definitiva a nuestras vivencias; la presencia de problemáticas especificas del "etcrno feminino" cn transformación; la inexistencia de una sintaxi lingúistica especificamente "feminina" (como algunos pretendem probrar); la evidencia de yue el valor literario de una obra no resulta del sexo del autor o autora, sino del talento de cada uno; y, por tillimo, la importancia básica que esa literatura asume mara un posibile y necesirio conocimiento de las transformaciones esiructurales cue, hoy, atralan la Suciedad y la C'ultura heredadas. 